\title{
Acid and base recovery from brine solution using PVP intermediate-based bipolar membrane through water splitting technology
}

\author{
Krishnaveni Venugopal $^{1} \cdot$ Minnoli Murugappan $^{1} \cdot$ Sangeetha Dharmalingam $^{1}$
}

Received: 20 March 2015/ Accepted: 25 September 2015/Published online: 27 October 2015

(C) The Author(s) 2015. This article is published with open access at Springerlink.com

\begin{abstract}
Potable water has become a scarce resource in many countries. In fact, the world is not running out of water, but rather, the relatively fixed quantity is becoming too contaminated for many applications. Hence, the present work was designed to evaluate the desalination efficiency of resin and glass fiber-reinforced Polysulfone polymerbased monopolar and bipolar (BPM) ion exchange membranes (with polyvinyl pyrrolidone as the intermediate layer) on a real sample brine solution for $8 \mathrm{~h}$ duration. The prepared ion exchange membranes (IEMs) were characterized using FTIR, SEM, TGA, water absorption, and contact angle measurements. The BPM efficiency, electrical conductivity, salinity, sodium, and chloride ion concentration were evaluated for both prepared and commercial-based IEM systems. The current efficiency and energy consumption values obtained during BPMED process were found to be $45 \%$ and $0.41 \mathrm{Wh}$ for RPSu-PVPbased IEM system and $38 \%$ and $1.60 \mathrm{Wh}$ for PSDVBbased IEM system, respectively.
\end{abstract}

Keywords Brine water desalination - Reinforced IEM · PVP intermediate based BPM - Water dissociation reaction . BPM efficiency

Sangeetha Dharmalingam

sangeetha@annauniv.edu

1 Department of Mechanical Engineering, Anna University, Guindy, Chennai, Tamil Nadu 600025, India

\section{Introduction}

Potable water has become a scarce resource in many countries, developed and developing alike. In India, there are many villages and towns which do not have adequate and reliable sources of drinking water of required qualities. This is mainly due to factors like saline underground water, contaminated water absolutely unfit for human consumption, dug up wells that yield water of poor quality, and dry up in summer. No source attracts such special attention as the problem of water supply in the current scenario. Hence it becomes essential to find a source for drinking water from other water bodies such as brackish water, sea water, sewage water etc., using suitable techniques. Desalination is one such technique, with its various categories it could be effectively used for water purification. Among the various categories, membrane-based technology is the most popular method for its wide application.

Membranes especially a class of ion exchange membranes (IEMs) is one of the advanced technological products mainly used for various industrial applications such as potable water production from the sea through reverse osmosis, recovery of valuable constituents from industrial effluents through the electrolysis process (Volkov et al. 2008; Ostwald 1890) etc. Recently, a special kind of IEM called as bipolar membranes (BPMs) or catalytic membranes have been developed for electro-membrane processes to split water into protons and hydroxyl ions (Kressman and Tye 1956; Frilette 1956). From the literature survey, it was identified that to meet the growing requirements of science and technology, several attempts were made to modify the existing IEMs. And surface modification of the membranes was observed as one of the ways that could be employed to minimize the undesired properties and also to introduce the additional functional 
properties for a polymer separation membrane (Ulbricht 2006).

On similar lines, the work in the present study was designed to evaluate the desalination efficiency of resin and glass fiber-reinforced Polysulfone (PSu) polymer-based monopolar (cation exchange and anion exchange) and bipolar [with polyvinyl pyrrolidone (PVP) as the intermediate layer (IL)] ion exchange membranes in terms of various process parameters on a real sample brine solution containing $10,000 \mathrm{ppm}$ up to $8 \mathrm{~h}$. The prepared IEMs were characterized using FTIR, SEM, TGA, contact angle measurements, and laboratory technique. In addition, the water dissociation capacity of the prepared BPM with PVP intermediates was tested in a two compartment electrodialytic cell that was fabricated in laboratory scale. The experimental results were compared with the results obtained by using commercially available polystyrene divinylbenzene-based (PSDVB) membranes under similar experimental conditions. In addition, for all the obtained final feed solutions after the performance, sodium-chloride ion concentration, salinity, and electrical conductivity of ions were determined.

\section{Materials and methods}

\section{Preparation of reinforced IEMs}

Anionic and cationic functionalized PSu-based ionomers (i.e., QPSu and SPSu ionomers) were obtained as reported earlier (Krishnaveni and Sangeetha 2012). To introduce additional functional properties like higher ion exchange capacity (IEC) with firmness and strength for a polymer separation membrane, reinforced CEM (RCEM) i.e., reinforced sulfonated Polysulfone (RSPSu) and reinforced AEM (RAEM) i.e., reinforced quaternized Polysulfone (RQPSu) were prepared with resin and glass fiber reinforcement in the synthesized cationic and anionic ionomers. Weighed amount of ion exchange resin (IER) was dried in an oven at $60{ }^{\circ} \mathrm{C}$ for $24 \mathrm{~h}$ before use. RCEM/ RAEM based on PSu polymer was prepared by first dispersing a specific quantity (from 10 to $70 \%$ ) of dried (60 ${ }^{\circ} \mathrm{C}$ for $24 \mathrm{~h}$ in an oven) and crushed CER/AER in either SPSu-N, $N^{\prime}$-dimethylformamide (DMF), or QPSuDMF solution respectively for $12 \mathrm{~h}$ using a magnetic stirrer at room temperature. In order to break the aggregates and to obtain a uniform dispersion, the solution was sonicated for $30 \mathrm{~min}$. Then, the solution was cast on a clean glass petri dish and the glass fiber matrix was placed to get immersed in the solution before drying in the oven for $24 \mathrm{~h}$ at $80{ }^{\circ} \mathrm{C}$. The conductivity for the obtained membranes with various resin contents was determined using impe- dance spectroscopy. For this, the membranes with required dimensions were cut and pretreated with $0.01 \mathrm{~N}$ sulfuric acid and kept in water for $100 \%$ hydration. From the difference between the resistance of the blank cell and the one with a membrane separating the working and counter electrode compartments, the resistance of the membrane was calculated and then it was converted to their conductivity values. From the results (Krishnaveni and Sangeetha 2015) it was confirmed that the conductivity of the prepared membranes, increased with increase in IER loading below $50 \%$, beyond which the membranes became brittle (Kumar and Shahi 2010). Hence, the resin loading was optimized at $40 \%$ for both resins.

The prepared RCEM and RAEM from PSu polymer were cut into pieces of $10 \mathrm{~cm} \times 12 \mathrm{~cm}$ size and pretreated using $1 \mathrm{M} \mathrm{NaOH}$ and $1 \mathrm{M} \mathrm{HCl}$ solutions then finally equilibrated with $2 \mathrm{M} \mathrm{NaCl}$ solution, washed with distilled water, and dried. Now these both layers act as cationic exchange layer (CEL) and anionic exchange layer (AEL) for the reinforced BPM (RBPM). Then on one side of both CEL and AEL layers, a solution containing approximately $0.12 \mathrm{~g}$ of PVP-based conducting polymer in $6 \mathrm{~mL}$ of ethanol solvent was coated to form the IL. Finally the ILcoated sides of both layers (CEL and AEL) were sandwiched and subjected to hot press for $5 \mathrm{~min}$ at a temperature and pressure of about $90{ }^{\circ} \mathrm{C}$ and 3 ton, respectively, and the finally obtained RBPM is now represented as RBPM-PVP.

\section{Reinforced IEM characterization}

The resin incorporation into functionalized membranes was confirmed with Perkin Elmer RX I FTIR spectrophotometer. The thermal stability of the prepared membranes was studied using SDT Q 600 US analyzer (ASTM E1131) under a nitrogen atmosphere at a heating rate of $20{ }^{\circ} \mathrm{C} \min ^{-1}$ from RT to $700{ }^{\circ} \mathrm{C}$. The surface morphology of the membranes was obtained using field emission HITACHI S-3400 SEM instrument. The hydrophilic and hydrophobic nature of the membrane was studied using Goniometer-sessile drop meter GBX-Digi-drop wetting and spreading studies. The conductivity of the membrane was determined using impedance spectroscopy. The characterization studies such as water absorption and IEC for the prepared membranes were measured using the similar procedure as discussed earlier (Krishnaveni and Sangeetha 2012). The chemical stability of the membranes was determined by accelerating the degradation process in the membranes using a solution containing $4 \mathrm{ppm}$ of ammonium iron (II) sulfate hexahydrate and $15 \mathrm{ml}$ of $\mathrm{H}_{2} \mathrm{O}_{2}$ (3\%) (Fenton's reagent) in $500 \mathrm{ml}$ distilled water at $60{ }^{\circ} \mathrm{C}$ for about an hour. 


\section{Electrodialytic IEM stack for brine desalination}

The fabricated bipolar membrane electrodialysis (BPMED) unit and the commercial PSDVB-based BPM used in the study were supplied by Arun Electrochemical, Chennai. The description of the instrument used for determination of both BPM efficiency and brine desalination is laboratory scale fabricated two compartments and five compartments electrodialytic cells. The volume of each chamber was about $160 \mathrm{~cm}^{3}$ and was connected to a tank of $1 \mathrm{~L}$ capacity of the distilled water solution, allowing for batch mode recirculation of external solutions by submersible pumps. The effective membrane areas of each IEM are about $120 \mathrm{~cm}^{2}$. The configuration of the membrane arrangement in the five compartments stack was in the order BP-A-C-BP in between the electrodes. The cathode and anode electrodes used were stainless steel and $\mathrm{Ti}$ coated with $\mathrm{Ti}-\mathrm{Ru}-\mathrm{Pd}$ oxides, respectively. The two electrodes were connected to a DC power supply. The two electrolyte compartments (EC) were on both the extremes adjacent to electrodes, two concentrated compartments [acid compartment (AC) and base compartment (BC)] adjacent to the central compartment on either side where acid and base were collected, and one dilute central feed compartment (FC) where sample to be treated are taken. The commercial monopolar membranes (CMI-7000S and AMI-7001S) used for comparison was purchased from International INC, New Jersey, USA.

In order to minimize the cell voltage generated during the initial stages of the experiments, dilute $\mathrm{HCl}$ $(0.01 \mathrm{~N})$ and dilute $\mathrm{NaOH}(0.01 \mathrm{~N})$ solutions were used in $\mathrm{AC}$ and $\mathrm{BC}$, respectively. And $0.05 \mathrm{~mol} \mathrm{~L}^{-1}$ of $\mathrm{NaCl}$ solution was taken in each EC. The experiments were carried out at the initial voltage of $10 \mathrm{~V}$. During the performance, at every $15 \mathrm{~min}$ time interval, process parameters such as membrane stack potential, $\mathrm{pH}$ (in $\mathrm{AC}, \mathrm{BC}, \mathrm{EC}$, and $\mathrm{FC}$ ), and acid-base concentration of the solutions (in $\mathrm{AC}$ and $\mathrm{BC}$ ) were determined by means of digital multimeters, $\mathrm{pH}$ meter (Hanna HI 96107 pocket size $\mathrm{pH}$ meter), and standard acid-base titration procedure, respectively. In addition, other parameters such as energy consumption, current efficiency (CE), Transport number (T. No.) of ions, water dissociation efficiency (WDE), and water dissociation flux were determined using the same set of equations as reported earlier (Krishnaveni and Sangeetha 2014a, b). Finally, after $8 \mathrm{~h}$ treatment, the feed sample was analyzed for their salinity and electrical conductivity using WTW LF 197-S EC meter. The chloride ion and sodium ion concentrations in these samples were measured by argentometric method and flame photometry, respectively.

\section{Results and discussion}

\section{FTIR characterization}

Pristine Polysulfone (PSu), RCEM (i.e., RSPSu) and RAEM (i.e., RQPSu) membrane samples were characterized using FTIR (Fig. 1) to confirm their structure and reinforced resin incorporation. The appearance of bands at 3026 and $756 \mathrm{~cm}^{-1}$ in Fig. 2a was due to the $v_{\mathrm{s}}(\mathrm{C}-\mathrm{H})$ and $\delta(\mathrm{C}-\mathrm{H})$ vibration bond of aromatic hydrocarbons, respectively. Appearance of bands at 1411 and $1387 \mathrm{~cm}^{-1}$ was due to the aliphatic $v_{\mathrm{as}}(\mathrm{C}-\mathrm{H})$ and $v_{\mathrm{s}}(\mathrm{C}-\mathrm{H})$ vibration, respectively. A doublet peak at $1589 \mathrm{~cm}^{-1}$ was due to Aromatic $v_{\mathrm{s}}(\mathrm{C}=\mathrm{C})$ vibration. The peaks at 1163 and $1320 \mathrm{~cm}^{-1}$ were due to the $v_{\mathrm{s}}\left(\mathrm{SO}_{2}\right)$ and $v_{\mathrm{as}}\left(\mathrm{SO}_{2}\right)$ group vibration, respectively. The peak at $692 \mathrm{~cm}^{-1}$ was due to $v$ (C-S) vibration and peak at 1113 and $1298 \mathrm{~cm}^{-1}$ represents $v_{\mathrm{s}}(\mathrm{C}-\mathrm{O}-\mathrm{C})$ and $v_{\text {as }}(\mathrm{C}-\mathrm{O}-\mathrm{C})$ vibrations, respectively. The appearance of all these peaks confirmed the structure of PSu. The appearance of a broad and intense envelope around $3447 \mathrm{~cm}^{-1}$ (Fig. 1b) was attributed to $-\mathrm{OH}$ stretch of the sulfonic acid group (present in both resin and membrane matrix) while the peak around $1161 \mathrm{~cm}^{-1}$ was due to the $\mathrm{O}=\mathrm{S}=\mathrm{O}$ (asymmetric stretch) group and this confirmed the sulfonation of PSu. The appearance of a peak at around $854 \mathrm{~cm}^{-1}$ suggested that the sulfonic acid group was substituted at the para position. The broad peak at $3392 \mathrm{~cm}^{-1}$ in Fig. 1c was assigned to the characteristic peak of $v_{\text {as }}\left(\mathrm{NR}_{3}{ }^{+}\right)$. Appearance of peak around $1320 \mathrm{~cm}^{-1}$ was due to $\mathrm{C}-\mathrm{N}$ stretching, vibration, and this confirmed the presence of amine group in the membrane matrix. From the peak intensity obtained, it was clear that resin

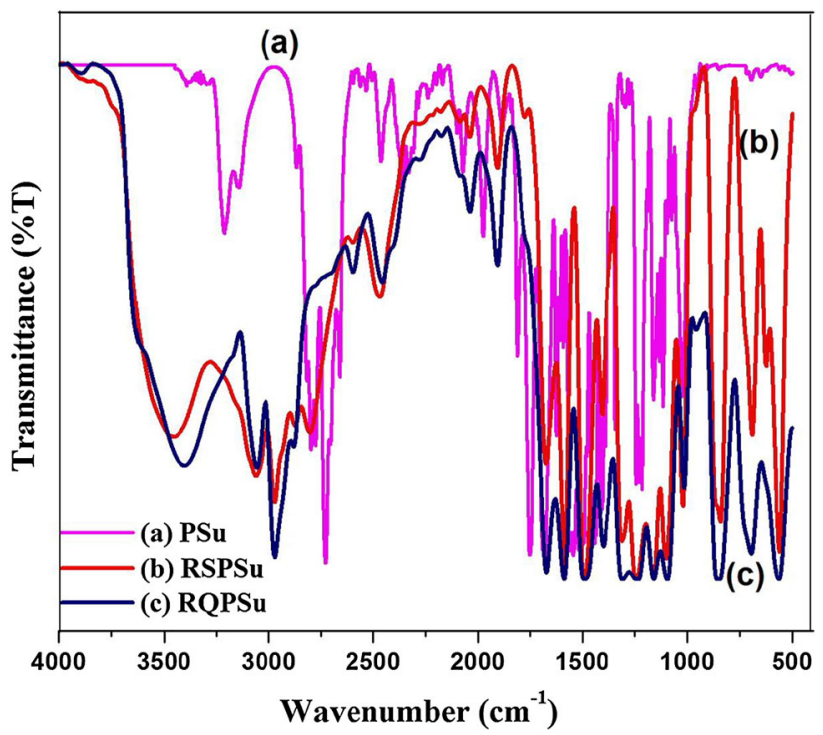

Fig. 1 FTIR spectra of $a$ PSu, $b$ RSPSu, and $c$ RQPSu membranes 


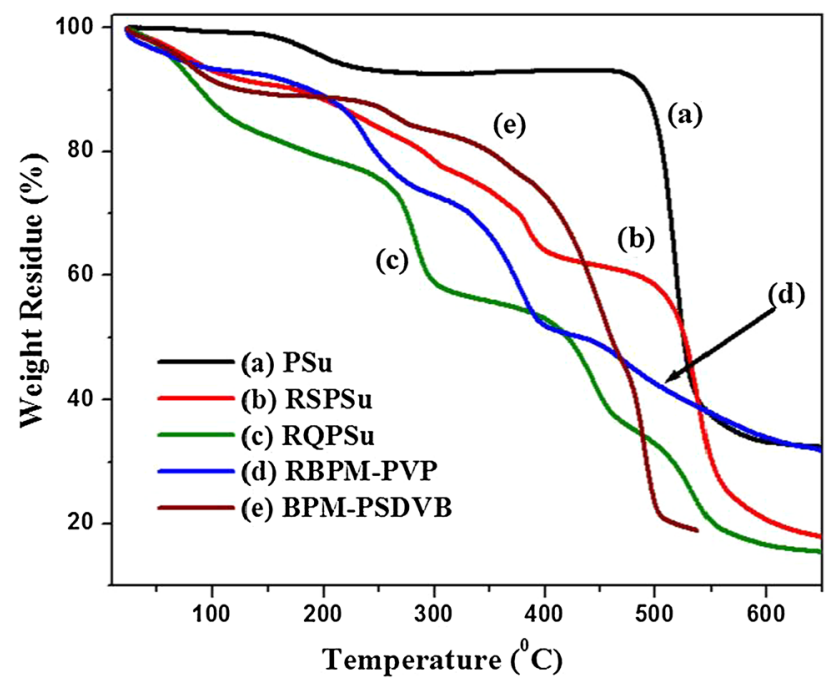

Fig. 2 TGA curves of $a$ PSu, $b$ RSPSu, $c$ RQPSu, $d$ RBPM-PVP, and $e$ BPM-PSDVB membranes

incorporation, in addition to quaternization and sulfonation reactions, resulted in an increase in the number of ion exchange groups in the membrane.

\section{Thermogravimetric analysis}

The TGA curves for the reinforced monopolar and BPM are shown in Fig. 2. The reasons for the observed various degradation steps at different temperatures for both commercial and synthesized IEM are given in Table 1. The TGA curve of pristine PSu as observed in Fig. 2a, exhibits two stage degradation. The first step indicated the loss of bound water and traces of solvent up to $270{ }^{\circ} \mathrm{C}$ and beyond which no further weight loss was observed until $476{ }^{\circ} \mathrm{C}$. The steep loss in weight observed beyond $490{ }^{\circ} \mathrm{C}$ was indicative of the polymer degradation.

\section{SEM analysis}

The SEM images of various IEMs such as RSPSu, RQPSu, and RBPM-PVP are shown in Fig. 3. The uniform distribution of resin particles throughout the reinforced membrane surface was observed for RSPSu and RQPSu membranes. On the other hand, cross-sectional view of reinforced PSu-PVP-based BPM clearly showed three distinct regions. The top layer was an anion exchange layer (AEL) or QPSu while the thin middle one represented the PVP-IL. The last layer (third layer) corresponded to cation exchange layer (CEL) or SPSu. The appearance of small spheres on both top and bottom surfaces of an RBPM-PVP represents the IER particles.

\section{Contact angle measurement}

From Fig. 4 on comparisons between the average contact angle of pristine $\left(82.51^{\circ}\right)$, PVP-coated membranes $\left(50.25^{\circ}\right)$ and reinforced functionalized membranes, it was identified that the introduction of functional group converted hydrophobic nature of the base polymer (pristine) into hydrophilic nature with a small contact angle measurement value as studied by Dias and de Pinho (1999) and Guan et al. (2005). Also, the contact angles for the commercial monopolar membranes such as CEM-PSDVB and AEMPSDVB were measured to be $86.70^{\circ}$ and $93.09^{\circ}$, respectively. A contact angle value for the reinforced functionalized membranes such as RSPSu and RQPSu could not be measured because of the complete absorption of water. This infers the increased hydrophilicity of these membranes than the pristine membrane due to the presence of functional groups, resin, and fiber reinforcements (Sachdeva et al. 2008). In order to determine the nature of PVP intermediate in a BPM, one face of the membrane was coated with PVP solution and its contact angle was measured.

Table 1 Representation of degradation temperature and its reason for various IEMs

Reason for degradation

\begin{tabular}{|c|c|c|c|}
\hline \multicolumn{4}{|c|}{ Membrane code with degradation temperature } \\
\hline $\begin{array}{l}\text { RSPSu (3 steps as } \\
\text { from Fig. } 2 b \text { ) }\end{array}$ & $\begin{array}{l}\text { RQPSu (3 steps as } \\
\text { from Fig. 2c) }\end{array}$ & $\begin{array}{l}\text { RBPM-PVP ( } 4 \\
\text { steps as from } \\
\text { Fig. 2d) }\end{array}$ & $\begin{array}{l}\text { PSDVB (3 steps } \\
\text { as from Fig. 2e) }\end{array}$ \\
\hline Up to $152{ }^{\circ} \mathrm{C}$ & Up to $137^{\circ} \mathrm{C}$ & Up to $131{ }^{\circ} \mathrm{C}$ & Up to $129^{\circ} \mathrm{C}$ \\
\hline $\begin{array}{l}\text { Between } 366 \text { and } \\
\quad 438{ }^{\circ} \mathrm{C} \\
\left(-\mathrm{SO}_{3} \mathrm{H}\right)\end{array}$ & $\begin{array}{l}\text { Between } 266 \text { and } \\
\quad 404{ }^{\circ} \mathrm{C} \\
\left(-\mathrm{NR}_{3}^{+}\right)\end{array}$ & $\begin{array}{l}\text { Between } 202 \text { and } \\
309^{\circ} \mathrm{C} \text { (both) }\end{array}$ & $\begin{array}{l}\text { Between } 249 \text { and } \\
311^{\circ} \mathrm{C} \text { (both) }\end{array}$ \\
\hline- & - & $\begin{array}{l}\text { Between } 334 \text { and } \\
453{ }^{\circ} \mathrm{C}\left(-\mathrm{NR}_{3}{ }^{+}\right)\end{array}$ & - \\
\hline
\end{tabular}

Regradation of intermediate molecule form the membrane
Removal of loosely bound resin particles on surface and from polymer matrix

Removal of reinforced fiber from the polymer matrix Polymer main chain degradation

Between 504 and $578{ }^{\circ} \mathrm{C}$ 

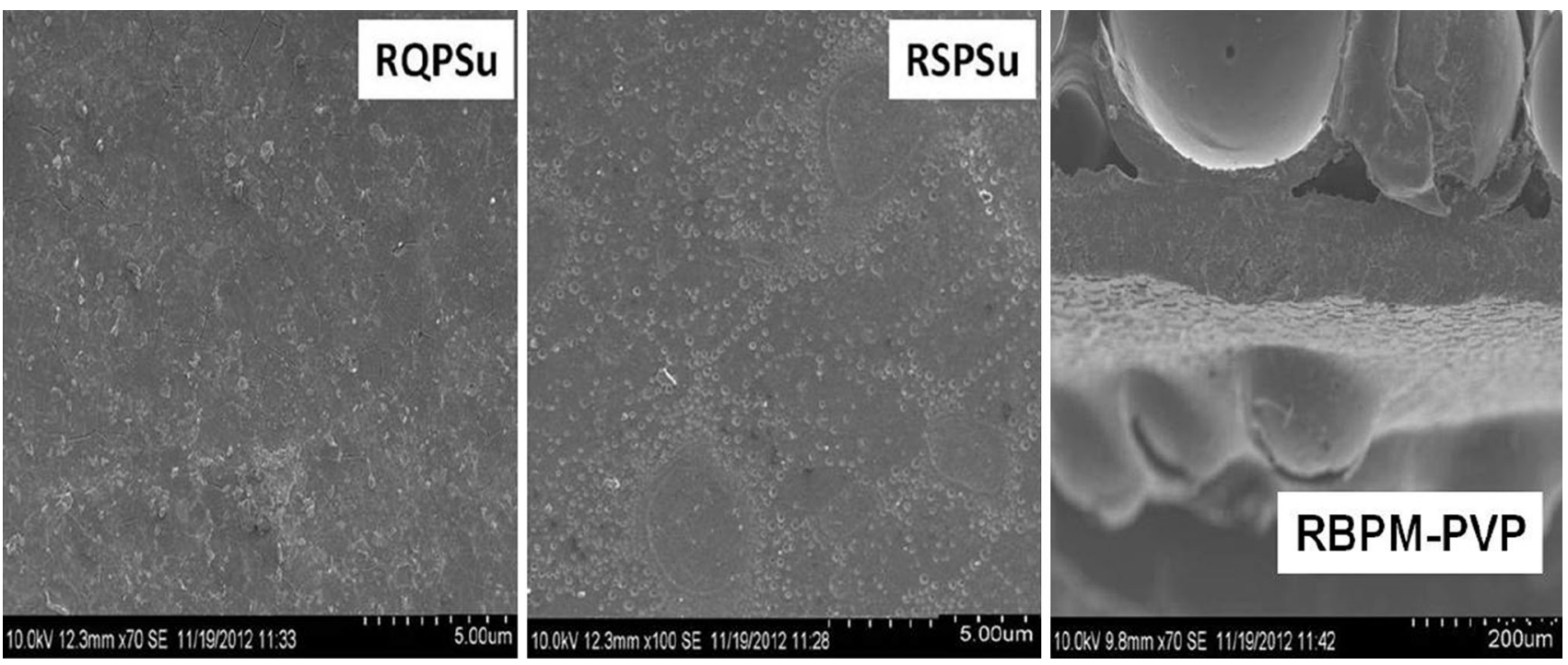

Fig. 3 SEM images of RSPSu, RQPSu, and RBPM-PVP membranes

Fig. 4 Contact angle of a water droplet on various polymeric membrane surfaces

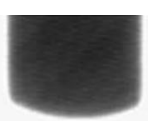

AEM-PSDVB
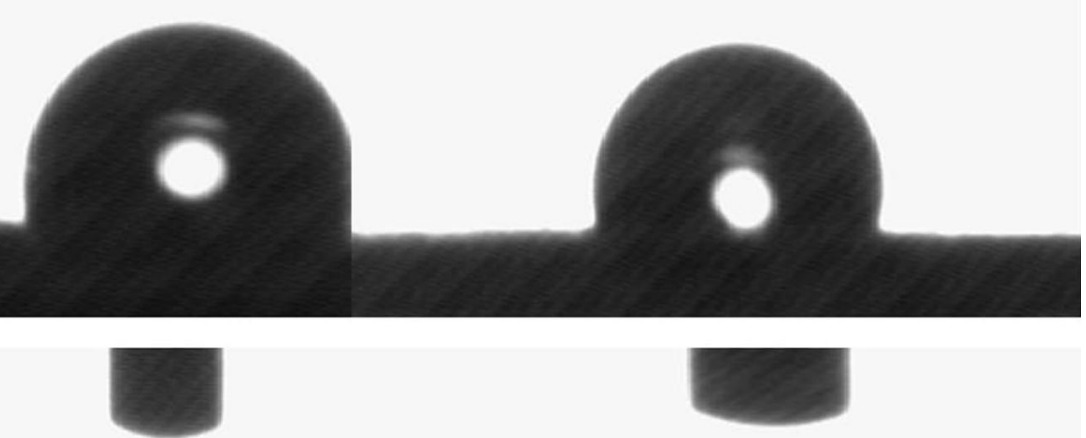

PSu

PVP coated

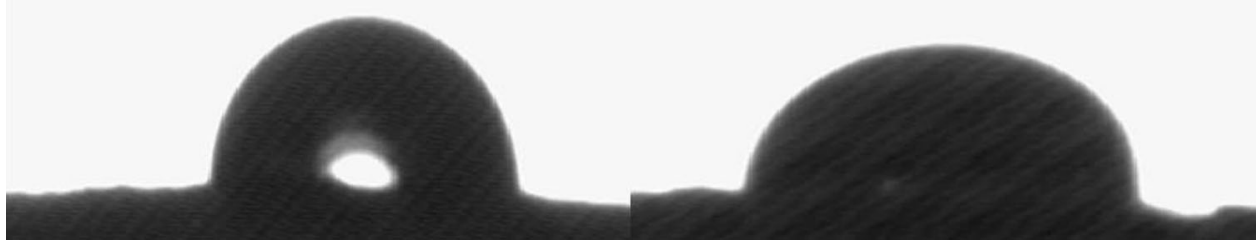

\section{Chemical stability}

To determine the suitability of the prepared reinforced IEMs and commercial IEMs in BPMED unit, all the membranes were treated under Fenton's reagent, so that the peroxide which was generated attacks the polymer chain leading to a fastening of the degradation potential. Then the subjected samples were then checked for their water absorption, IEC, and conductivity values as per the standard procedures and the values are tabulated in Table 2 . 
Though the reinforced fiber present in the polymer chain held the ion exchange functional groups strongly, because of this enhanced degrading mechanism, the incorporated hydrophilic resin particles, and functional group that are present on the surface get leached out from the membrane due to loosing of the fiber materials upon swelling resulting in lower value when compared with its initial value ( $\mathrm{Zhu}$ et al. 2008).

\section{RPSu-PVP- and PSDVB-based BPM characterization}

\section{$p H$ variation with time}

Since BPM consists of RCEM and RAEM as CEL and AEL layers, respectively, which are joined together using catalytic PVP as IL, when it was placed in between the electrodes due to large electric field appearing at the membrane interface, an excess $\mathrm{OH}^{-}$and $\mathrm{H}^{+}$ions were produced by the enhanced chemical reaction. This then migrated through the ion exchange layers into the distilled water-filled compartments resulting in the formation of acid and base. This principle has been depicted in Fig. 5 .

Confirmation of RPSu-PVP-based membrane possessing BPM characteristics was done by analyzing the acid and base yield in the neighboring compartments as shown by changes in $\mathrm{pH}$ measurements. Initially the $\mathrm{pH}$ meter was optimized before taking readings using the distilled water. From Fig. 5 it is obvious that with increase in time, the $\mathrm{pH}$ of the solutions in the two compartments changed from its initial distilled water value. The compartment closer to the anode side was found to be basic in nature and the one closer to the cathode side was acidic in nature. The increasing trend in $\mathrm{pH}$ change with time confirmed that some ions were newly introduced only during the performance due to certain in situ reactions. And these ions were probably protons and hydroxyl ions formed on either side of the BPM by means of water splitting into its ions under the electrical driving force between the electrodes. This conclusion was arrived at ease since there was no possibility of any other ions being present by chance since only distilled water was taken in both the compartments. On comparing RPSu-PVP-based BPM with that of commercial PSDVB-based BPM, from Fig. 5, it was found that RPSuPVP-based BPM produced a more acidic solution than PSDVB-based BPM. In the case of basic solution, similar results were observed expecting that RPSu-PVP-based BPM took longer time to reach its highest base $\mathrm{pH}$ value than PSDVB-based BPM due to leakage of ions in the initial stage to the neighboring compartment.

\section{Concentration changes with time}

In the case of acid and base concentration as per Fig. 6, both RPSu-PVP- and PSDVB-based BPMs required lesser time to attain maximum acid concentration of about $0.004 \mathrm{~N}$ than to attain same base concentrations as revealed in $\mathrm{pH}$ change. Additionally, between the two BPMs, RPSuPVP-based BPM took less time to attain maximum concentrations for both acid and base when compared to PSDVB-based BPM. In both BPMs, once the higher concentration was reached in both $\mathrm{AC}$ and $\mathrm{BC}$; decrease in concentration was observed for BPM which exhibited a higher leakage capacity and was observed to get leveled off without further rise or decrease if the leakage was not much favored in BPM. Hence, from the above discussion and Fig. 6, it was confirmed that RPSu-PVP-based BPM showed a better BPM performance than PSDVB-based BPM. Although both BPMs showed the concentration leveling finally, after attaining its maximum in both the compartments, the difference in time taken to reach the maximum acid and base concentration was considered for this inference. In the case of RPSu-PVP-based BPM, through a steady increase in concentration, highest acid and base concentration was finally attained at 1 and $1 \frac{1}{2} \mathrm{~h}$, respectively, while for PSDVB-based BPM, it was 2 and $4 \mathrm{~h}$, respectively. Additionally, it should be noted that the increase in concentration was also not regular during the

Table 2 Chemical stability test for the prepared membranes

\begin{tabular}{|c|c|c|c|c|c|c|}
\hline \multirow[t]{2}{*}{ Membrane code } & \multicolumn{2}{|c|}{ IEC (meq $\mathrm{g}^{-1}$ ) } & \multicolumn{2}{|c|}{ Water absorption (\%) } & \multicolumn{2}{|c|}{ Conductivity $\left(10^{-3} \mathrm{~S} \mathrm{~cm}^{-1}\right)$} \\
\hline & Initial & Final & Initial & Final & Initial & Final \\
\hline RSPSu & 4.75 & 4.53 & 15.4 & 14.3 & 5.86 & 5.19 \\
\hline RQPSu & 4.35 & 4.12 & 11 & 9.9 & 5.28 & 4.86 \\
\hline RBPM-PVP & - & & 28 & 26.7 & 7.14 & 6.92 \\
\hline CEM-PSDVB & 1.6 & 1.5 & 6.5 & 5.4 & 4.86 & 4.64 \\
\hline AEM-PSDVB & 1.3 & 1.2 & 3.7 & 3.1 & 4.68 & 4.27 \\
\hline BPM-PSDVB & - & & 9 & 8.2 & 4.75 & 4.4 \\
\hline
\end{tabular}



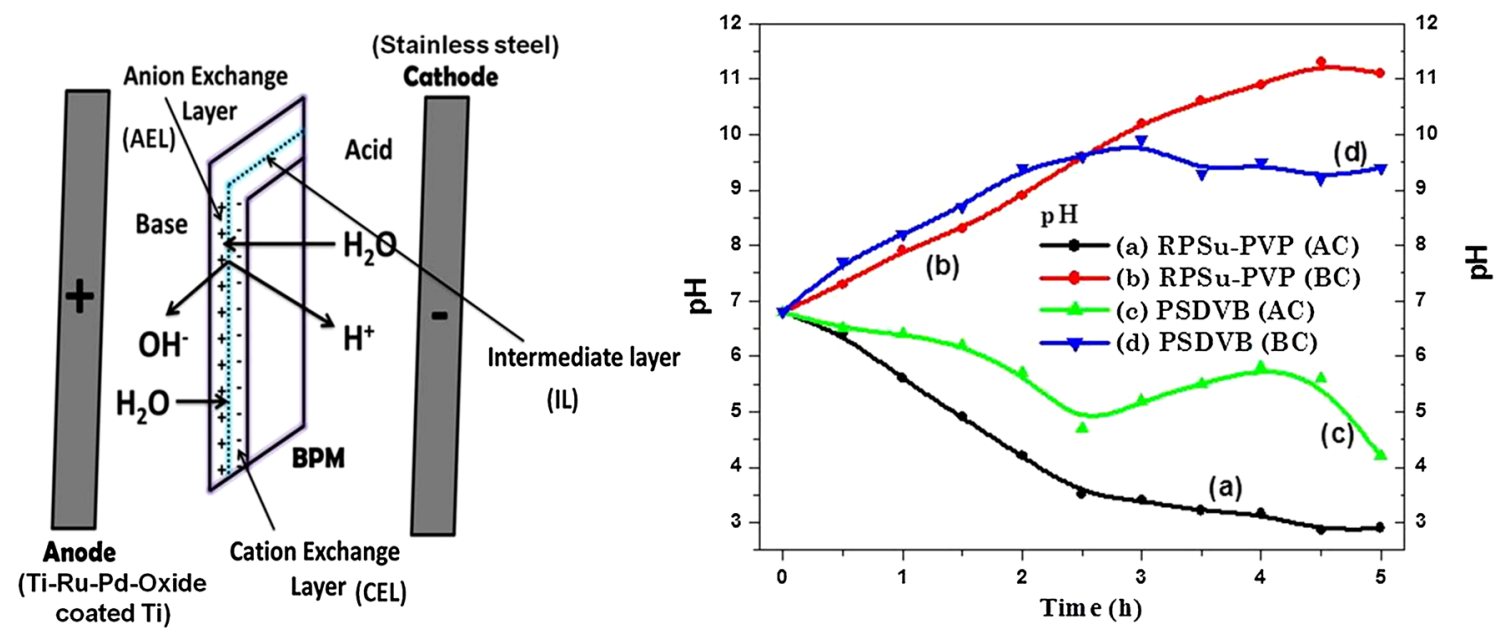

Fig. 5 Principle of BPM and Variation of $\mathrm{pH}$ with time in both compartments

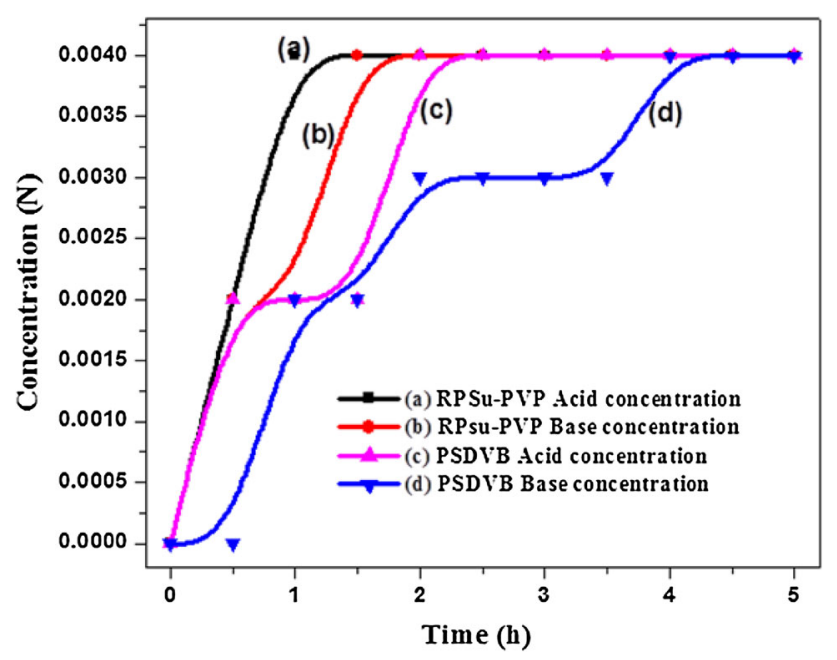

Fig. 6 Concentration change in both $\mathrm{AC}$ and $\mathrm{BC}$ with time

performance due to the leakage of ions for PSDVB-based BPM.

\section{Current-voltage relationship}

From Fig. 7, it is clear that no rectification was observed since the current was found under the applied voltage. However, the increase in current with increasing voltage proved the occurrence of water splitting in both the BPMs (Tanioka et al. 1999). On comparing the potential applied during the performance for both BPMs, RPSu-PVP-based BPM showed a higher value of up to 13.3 V than PSDVBbased BPM $(11 \mathrm{~V})$ for the same duration while the increase in current was observed to be lower in RPSu-PVP-based
BPM (maximum of about $47 \mathrm{~mA}$ ) than PSDVB-based BPM (maximum of about $52 \mathrm{~mA}$ ). Figure $7 \mathrm{a}, \mathrm{b}$ represents the typical steady state $\mathrm{I}-\mathrm{V}$ curve as reported by Kumar and Shahi (2010). In Fig. 7a, the variation in current due to ionic transportation was smaller when compared with Fig. 7b. This magnitude is a measure of BPM selectivity toward co-ion leakage, and may be used to predict its efficiency as per Aritomi et al. (1996). Hence, it could be concluded that RPSu-PVP-based BPM was expected to have better process efficiency due to lower co-ion leakage capacity when compared with PSDVB-based BPM. Beyond this potential, water dissociation occurs and the water splitting products $\left(\mathrm{OH}^{-} / \mathrm{H}^{+}\right)$also participated in the current transport which resulted in a steep increase in current. From this region, it could be clearly understood that the onset of water dissociation reaction occurred earlier in the case of RPSu-PVP-based BPM than PSDVBbased BPM. This in turn supports the discussion on $\mathrm{pH}$ and acid-base concentration of both BPM systems. The only reason for all the observed results was the difference between the two BPMs i.e., the presence of the PVP-based IL along with fiber and resin reinforcements in the case of RPSu-PVP-based BPM whereas such modification was absent in the PSDVB-based BPM system. Once the IL and resin were introduced it became more hydrophilic by attracting water from the IEL to the space charge region. The BPM, without any catalyst, increased the water dissociation resistance with an increase in current, because the water dissociation rate was slower than the ion transfer rate. The above results confirmed that the introduced PVP intermediate in RPSu-PVP-based BPM functions as a water dissociation catalyst. 

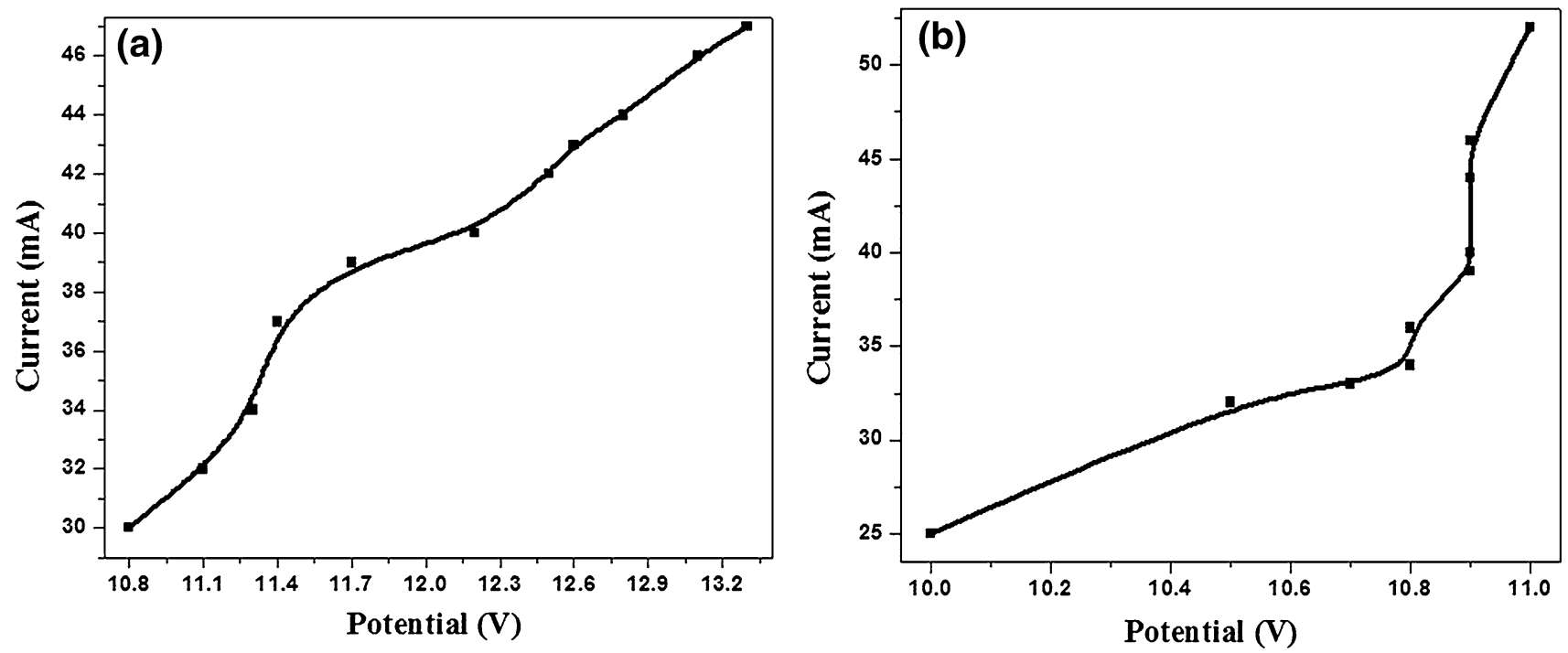

Fig. 7 Current-voltage curves for a RPSu-PVP-based BPM and b PSDVB-based BPM

\section{BPMED performance for brine desalination}

\section{Determination of $\mathrm{pH}$ changes with time}

Figure 8 represents the current-voltage measurement and changes of $\mathrm{pH}$, acid-base production with increasing time for both RSPSu-PVP and PSDVB-based IEM system. As an initial step, the $\mathrm{pH}$ of the solution in FC, EC, AC, and $\mathrm{BC}$ was observed at regular $15 \mathrm{~min}$ time intervals up to $8 \mathrm{~h}$ so as to clearly observe the mode of change of $\mathrm{pH}$ in these compartments. In the case of RPSu-PVP-based IEM system, the $\mathrm{pH}$ in $\mathrm{FC}$ was observed to increase toward basicity then decrease and finally become slightly acidic in nature which was similar to the results observed by Shen et al. (2013). This is because with increasing time, higher quantities of acid were produced due to water dissociated products and thereby resulting in proton leakage through IEMs depending upon the capacity of protons to undergo back diffusion. Due to its intrinsic mobility in the presence of water, FC remained slightly acidic in nature (Xu and Yang 2002; Wang et al. 2011; Trivedi et al. 1997). On the other hand, in the case of PSDVB-based IEM system, the
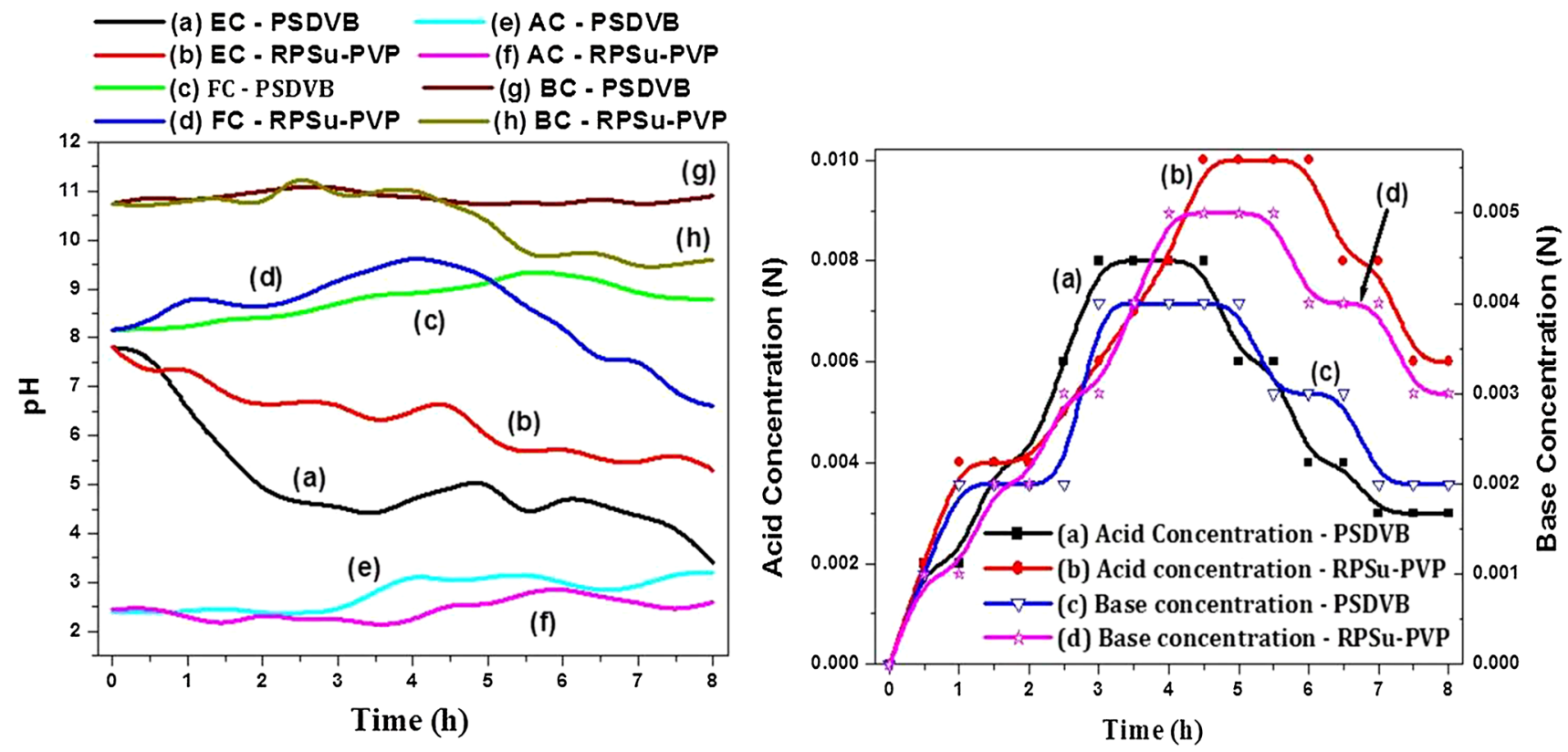

Fig. 8 Change in $\mathrm{pH}$ and acid-base yield with time 
feed solution finally became basic in nature. The difference in $\mathrm{pH}$ observed between the two different systems was mainly attributed to the leakage of ions occurring through the membranes between the compartments in a stack. PSDVB-based cell experienced greater leakage of ions from $\mathrm{BC}$ to $\mathrm{FC}$ and thus it remained basic in nature. Moreover, proton leakage through IEM was low due to low concentration of acid that was produced during BPMED process using PSDVB-based IEM systems (Strathmann and Koop 2000). In the case of EC, due to the initial addition of $0.05 \mathrm{M} \mathrm{NaCl}$ solution, the $\mathrm{pH}$ was observed to be slightly basic in nature at their initial stages which then was observed to decrease with time. Though both the IEM systems showed the final solution to be acidic nature, the acidity was greater in the case of PSDVB-based IEM system than observed with RPSu-PVP-based IEM system. The reason for this was attributed to the higher leakage of ions through commercial membranes than that observed with synthesized membranes.

From Fig. 8, it is clear that the initial $\mathrm{pH}$ in $\mathrm{AC}$ and $\mathrm{BC}$ remained to be in the range of $\sim 2.45$ and $\sim 10.74$, respectively, due to the addition of $0.01 \mathrm{~N}$ of acid and base solution into their respective compartments. Moreover, the $\mathrm{pH}$ in both $\mathrm{AC}$ and $\mathrm{BC}$ was found to rise marginally in their initial stages and was not uniform because of the leakage of certain ions into the neighboring compartments. Due to higher acid production, higher acidic $\mathrm{pH}$, and greater acid leakage were observed in case of RPSu-PVP-based IEM system when compared with PSDVB-based IEM system. Whereas, in the case of basic $\mathrm{pH}$, both the systems showed more or less the same $\mathrm{pH}$ during the first half stages of performance and later RPSu-PVP-based IEM system showed a little lower basic $\mathrm{pH}$ when compared with PSDVB-based IEM system. The $\mathrm{pH}$ change in $\mathrm{AC}$ and $\mathrm{BC}$ confirmed the acid-base production in their respective compartments which could also be confirmed by their concentration measurements. This $\mathrm{pH}$ variation in various compartments clearly suggested that both IEM-based systems possessed the capacity to split water into its co-ions under electric field (Shi et al. 2010; Badruzzaman et al. 2009).

\section{Determination of acid and base concentration}

When the entire ED cell was under an electric field using electrodes, the $\mathrm{Na}^{+}$and $\mathrm{Cl}^{-}$ions were continuously transported from $\mathrm{FC}$ into $\mathrm{BC}$ and $\mathrm{AC}$, respectively. In addition to this, due to the large electric field appearing at the membrane interface, an excess $\mathrm{OH}^{-}$and $\mathrm{H}^{+}$ions produced due to the field-enhanced chemical reaction also permeate through ion exchange layers of the BPM resulting in the formation of acid and base. From the $\mathrm{pH}$ studies, it was evident that acid and base of certain normality concentrations were produced in the $\mathrm{AC}$ and $\mathrm{BC}$, respectively, while using RPSu-PVP-based IEM system and PSDVB-based IEM system in BPMED stack (Wang et al. 2012). From Fig. 8, it can be noted that acid concentration of about $0.008 \mathrm{~N}$ was obtained which was the maximum in AC for PSDVB-based IEM system while it was $0.01 \mathrm{~N}$ for RPSu-PVP-based IEM system. Whereas, the maximum base concentration in $\mathrm{BC}$ was observed to be $0.004 \mathrm{~N}$ for PSDVB-based IEM system while it was $0.005 \mathrm{~N}$ for RPSuPVP-based IEM system during a brine desalination performance in BPMED.

PSDVB-based IEM cell is meant for base production rather than acid production because of higher specific permselectivity of CEM for $\mathrm{H}^{+}$ions as reported in the literature (Shen et al. 2013). However, from Fig. 8, the alkalinity concentration was observed to be lower in case of PSDVB-based IEM system. Furthermore, $\mathrm{H}^{+}$ions in the presence of water have a higher intrinsic mobility than $\mathrm{OH}^{-}$ions and thereby resulting in more leakage of $\mathrm{H}^{+}$ions through commercial AEM. The T. No. of protons through AEM increased with the produced acid concentration which would also lead to their low concentration in AC (Liu et al. 2013). The maximum concentration remained constant until certain duration of time after which it decreased with increase in processing time for both types of IEM system. This suggested that the mass transfer of $\mathrm{Na}^{+}$and $\mathrm{Cl}^{-}$ions through the IEM diminished due to the decrease of $\mathrm{NaCl}$ concentration in the feed solution. Together with the increase of the concentration of $\mathrm{Na}^{+}$and $\mathrm{Cl}^{-}$ions in $\mathrm{BC}$ and $\mathrm{AC}$, the molecular back diffusion through IEM caused by the high concentration gradient might hinder the transport of $\mathrm{Na}^{+}$and $\mathrm{Cl}^{-}$ions. Furthermore, the dissociation of water molecules was also enhanced due to the Second Wien effect.

\section{Current-volt measurement}

From Fig. 9, the current and voltage were observed to be directly proportional to each other, thereby proving that water was split at the BPM junction of RPSu-PVP-based IEM system. Also, in order to avoid high resistance, the membrane thickness used to be as thin as possible (Blaster et al. 2010). For RPSu-PVP and PSDVB-based IEM system the maximum potential points observed were 11.8 and $22.5 \mathrm{~V}$, respectively, while the maximum current values observed for the same were 57 and $89 \mathrm{~mA}$, respectively. The observed low voltage for RPSu-PVP-based IEM system could be explained theoretically using protonation and de-protonation reaction model and the hydrophilicity change in the interface (Fu et al. 2003). The presence of hydrogen bonding and polar interactions between the intermediate PVP and water molecules speeds up the water dissociation into hydrogen and hydroxyl ions. Thus, the 


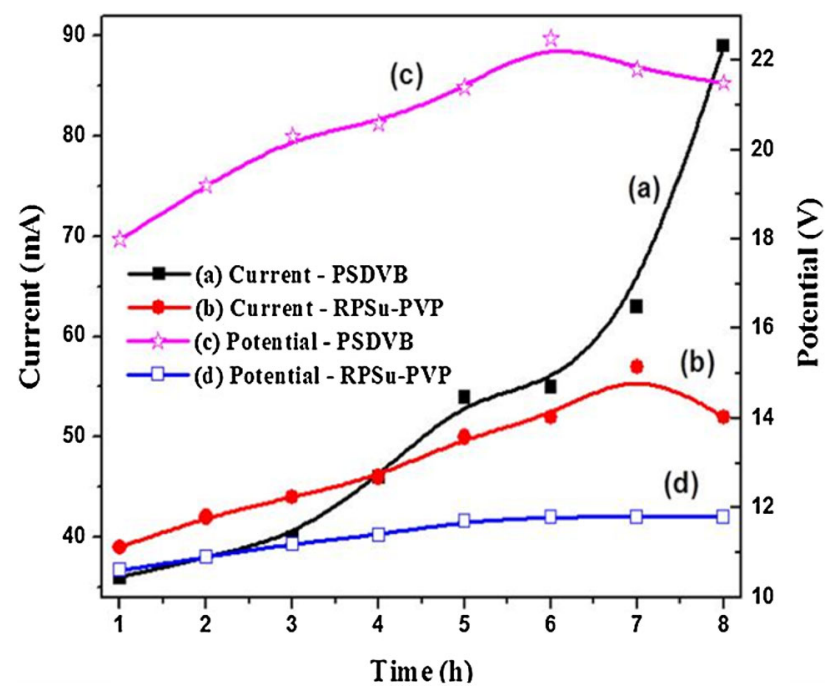

Fig. 9 Change in current and potential with time

voltage across the membrane falls and the potential decreases. On the other hand, PVP is a kind of strong hydrophilic substance and when used as an intermediate the number of hydrophilic sites in the interfacial region increased due to the high absorption of PVP which in turn increased the efficiency of water splitting.

In case of current variation with time, it was observed to increase with time for both RPSu-PVP and PSDVB-based IEM systems as shown in Fig. 9 because of the production of $\mathrm{OH}^{-} / \mathrm{H}^{+}$during water dissociation. In other words, at the beginning of the experiments, $\mathrm{AC}$ and $\mathrm{BC}$ initially have distilled water with very low concentrations of acid and alkali. So the resistances offered by these compartments were very high as compared to the resistance offered by FC. As time passes, the concentrations of $\mathrm{AC}$ and $\mathrm{BC}$ increased because of the continuous formation of acid and alkali in these compartments and all the solutions were being continuously recycled. Hence, the resistance of these compartments was decreased. On the other hand, the concentration of salt in FC decreased due to the continuous transport of ions from these compartments. As a result, the resistance of these compartments increased. The net effect was the overall decrease in stack resistance with time, resulting in an increase in current production with time. But in the case of RPSu-PVP-based system, unlike that of the PSDVB-based system, the final current was slightly lower due to the concentration polarization phenomenon and difference in membrane resistance in the stack. The maximum current observed for both RPSu-PVP and PSDVB-based IEM systems was about 57 and $89 \mathrm{~mA}$, respectively.

In the case of voltage versus time curve, the curve which was inclined to be a line in parallel to the X-axis for both the cases, indicated that PSDVB and RPSu-PVP-based system were chemically stable when it was used for water dissociation as described by Xue et al. (2006). The purity of acid and alkali increased with an increase in voltage to some extent, after which further increase in voltage had an adverse effect on membranes, concentration, and purity of acids and bases depending upon the current rate of water dissociation on the IL surface of BPM as well as the rate of ion transport through the monopolar membranes. This was mainly because it causes heating of stack and deterioration of membrane properties as discussed by Trivedi et al. (1997).

\section{Determination of WDE, T. No. of ions, and fluxes}

The efficiency of BPMED is strongly affected by the transport properties of ions present in the solution through various functionalized IEMs. WDE is one of the most important parameters for determining the process efficiency, which was closely related to the membrane's transport properties. Under an electric field, at the beginning of the BPMED process, there was a competition between these ions for transport, and the transfer of a large amount of $\mathrm{Na}^{+}$and $\mathrm{Cl}^{-}$ions through the IEM resulted in a slow transfer of $\mathrm{H}^{+}$and $\mathrm{OH}^{-}$ions. This was because of the maximum availability of initial salt concentration in FC when compared with the water-dissociated ions. As the operation time passed, the dissociation of large amounts of water molecules resulted in the large accumulation of $\mathrm{H}^{+}$ and $\mathrm{OH}^{-}$. It should be noted that once all the $\mathrm{Na}^{+}$and $\mathrm{Cl}^{-}$ ions were transported from the $\mathrm{FC}$, the accumulated $\mathrm{H}^{+}$ and $\mathrm{OH}^{-}$were also transported very efficiently resulting in the higher WDE after the first half performance time. This also explained the reason for the observed higher T. No. of ions with time during the first half part of the performance and a decrease in its value during the later stages of performance for the same membrane (Shen et al. 2013).

Ion transport number is a quantity which is indicative of the different contributions of ions to the electric current in electrolytes due to their varied electrical mobility. Since $\mathrm{CE}$ depends upon the ion transport and ionic mobility of an ion for a better process efficiency it was expected that the system should have higher T. No. of ion. Figure 10 represents the T. No. properties of both sodium and chloride ions for RPSu-PVP-based and PSDVB-based IEM system, respectively. From Fig. 10 it is clear that T. No. of both $\mathrm{Na}^{+}$ion and $\mathrm{Cl}^{-}$ions decreased with increase in time for both the IEM systems. This was because $\mathrm{NaCl}$ concentration that was available for migration started to decrease with increase in time as discussed above. However, the performance was running steadily, mainly because the current was carried by the water dissociated products such as $\mathrm{H}^{+}$and $\mathrm{OH}^{-}$ions. Depending upon the membrane capacity the higher T. No. was observed to be its initial 
value. In both IEM systems, the chloride ion T. No. was observed to be greater than sodium ion T. No. value as reported in literature. The initially observed results for $\mathrm{T}$. No. of sodium and chloride ion, i.e., 0.11 and 0.33 values decreased to 0.04 and 0.08 , respectively, for RPSu-PVPbased system while in case of a PSDVB-based system, T. No. of sodium and chloride ion decreased from its initial of about 0.4 and 0.5 to 0.37 and 0.42 , respectively, in brine desalination performance.

Based upon the feed concentration, $\mathrm{pH}$ variations in $\mathrm{AC}$ and $\mathrm{BC}$ during the stack performance, time , and membrane capacity, the occurrence of water dissociation on BPM interface was confirmed. From Fig. 11, it is clear that WDE increased with increase in time. The reason for this variation of WDE with time is the same as discussed for T. No. of ions. The higher WDE of about 0.88 was obtained for RPSu-PVP and it was 0.21 for PSDVB-based IEM system. The highest T. No. and steady increase in WDE with time observed for RPSu-PVP-based IEM system was mainly due to the increase in electric field, pre-polarization of water molecules at the membrane-solution interface, and the presence of a hydrophilic catalytic PVP intermediate in between the two monopolar layers of BPM. According to Ren et al. (2008), the reduction in the ionic transport rate during later stages of the performance was often correlated with an increased membrane resistance due to the presence of a mixture of organic matter and inorganic salts. As a consequence, during the performance of brine desalination, slight membrane fouling was observed for both RPSuPVP-based and PSDVB-based IEM systems. It is also noted from Fig. 11 that in both cases, whether acidic or basic, the water dissociation fluxes decreased with time.

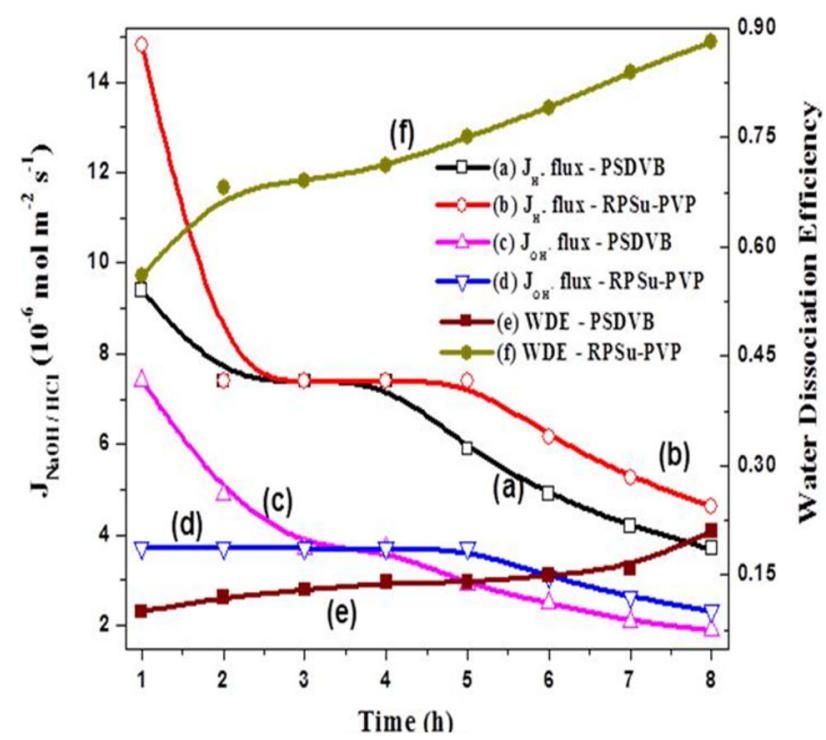

Fig. 10 Change in T. No. properties of both sodium and chloride ions with time

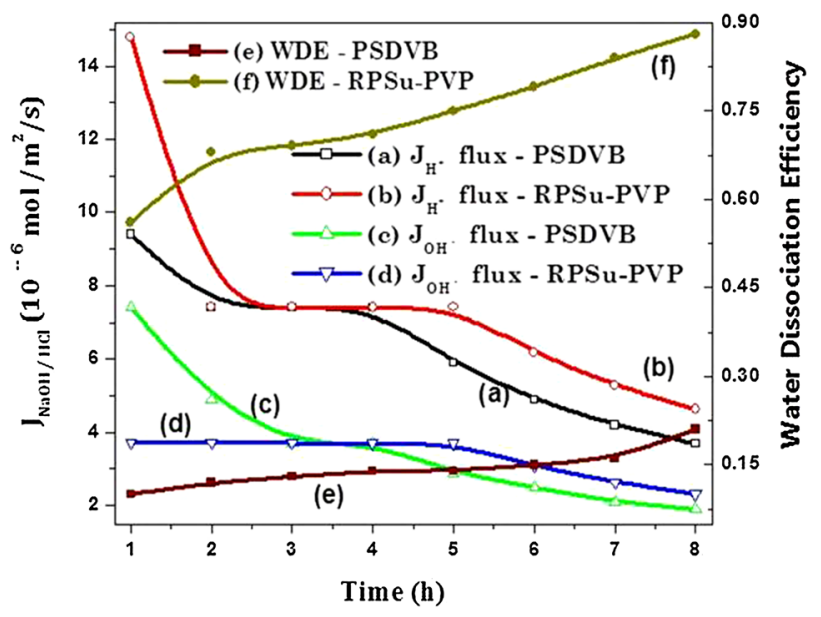

Fig. 11 Change in WDE and water dissociation fluxes of both proton and hydroxyl ion with time

The main reason for the decrease in acid and base flux was due to the depletion of $\mathrm{Na}^{+}$in anode compartment and $\mathrm{Cl}^{-}$ ion in cathode compartment and the availability of $\mathrm{NaCl}$ in FC for the conversion into the acid and base. Higher acidic and basic fluxes were observed to be $9.4 \times 10^{-6}$ and $7.4 \times 10^{-6} \mathrm{~mol} \mathrm{~m}^{-2} \mathrm{~s}^{-1}$ for PSDVB-based system and $14.8 \times 10^{-6}$ and $3.71 \times 10^{-6} \mathrm{~mol} \mathrm{~m}^{-2} \mathrm{~s}^{-1}$ for RPSuPVP-based systems, respectively.

\section{Determination of process efficiency parameters}

For any system, higher CE with lower energy consumption is one of the factors which determine the feasibility of electrochemical process toward higher process efficiency. It is clear from Fig. 12 that CE of BPMED stack decreased with operation time for both types of IEM systems. This can be explained by invoking the concept of ion leakage through IEM as discussed in the case of T. No. of ions. CE was observed to decrease from $38 \%$ with time for the PSDVB-based system while it was $45 \%$ for RPSu-PVPbased system. On the other hand, in the case of energy consumption, it increased with an increase in time as per shown in Fig. 12. The increase in the energy consumption was mainly attributed to the fact that a large part of the total electrical energy was consumed to overcome the electrical resistance. The applied voltage declined sharply at the start of the BPMED procedure. This was mainly related to either the increase in conductivity of the $\mathrm{HCl} /$ $\mathrm{NaOH}$ solution in $\mathrm{AC} / \mathrm{BC}$ or caused due to the exhaustion of $\mathrm{NaCl}$ in the feed solution. The increase in resistance of $\mathrm{FC}$, resulted from the exhaustion of $\mathrm{NaCl}$ in the solution, can be offset by a decrease in the electrical resistance of $\mathrm{AC}$ and $\mathrm{BC}$ caused by an increase in the $\mathrm{HCl}$ and $\mathrm{NaOH}$ concentrations as a consequence of transfer of $\mathrm{Cl}^{-}$and $\mathrm{Na}^{+}$ ions from the feed solution. Since the transformation of 


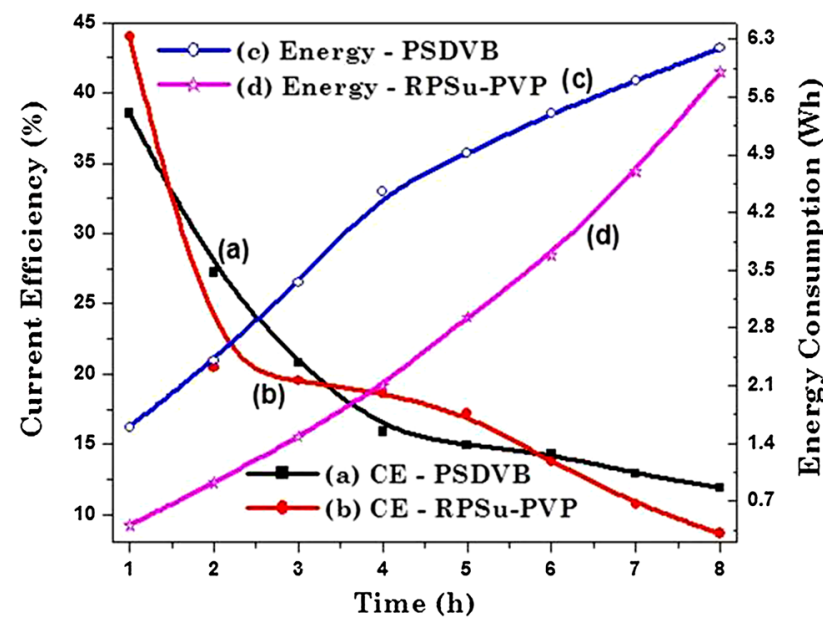

Fig. 12 Change in CE and energy consumption with time

$\mathrm{NaCl}$ into an acid and base solution was fully realized, the electrical resistance of feed solution increased, resulting in a sharp increase in the voltage drop. Thus, the energy consumption was observed to increase with time and reached a maximum of $6.2 \mathrm{Wh}$ for PSDVB-based system and 5.9 Wh for RPSu-PVP-based system.

\section{Determination of electrical conductivity, salinity, and sodium-chloride ion concentration}

To evaluate the purity of the generated acid and base during the performance and to confirm the capacity of both synthesized and commercial BPM regarding their efficiency to dissociate water into its ions, certain important parameters such as electrical conductivity, salinity, sodium ion, and chloride ion concentrations were analyzed. Table 3 represents the electrical conductivity, salinity, and sodium-chloride ion concentration values in $100 \mathrm{ml}$ of feed sample solutions for both RPSu-PVP and PSDVB-based IEM systems, respectively. Though the removal of $\mathrm{NaCl}$ ions from the FC was confirmed by its electrical conductivity measurements; the effectiveness of this process was confirmed by its salinity measurements. The observance of lower salinity and electrical conductivity than its initial value was mainly because of the migration of the salt ions from the FC toward the neighboring compartment. Thus, this result suggested that the water obtained after the BPMED desalination performance was expected to have a better quality than their initial sample.

With respect to sodium and chloride ion concentration, the final feed solutions showed a lower value than its initial salt sample solution for both ion concentrations in case of the two types of IEM systems. This clearly confirmed the migration of ions under the electric field from $\mathrm{FC}$ to neighboring compartment. The increase in final $\mathrm{Na}^{+}$and
Table 3 Electrical conductivity, salinity, and sodium-chloride ion concentration values for RPSu-PVP and PSDVB-based IEM systems

Parameters RPSu-PVP based IEM system PSDVB based IEM system

\begin{tabular}{lcc}
\hline \multicolumn{2}{l}{ Electrical conductivity $\left(\mathrm{mS} \mathrm{cm}^{-1}\right)$} \\
Initial & 17.17 & 17.17 \\
Final & 7.0 & 12.02 \\
Salinity $(\%)$ & & \\
Initial & 11.5 & 11.5 \\
Final & 5.1 & 7.9 \\
Chloride ion & concentration $\left[\mathrm{mg}(100 \mathrm{~mL})^{-1}\right]$ \\
Initial & 10.3 & 10.3 \\
Final & 6.6 & 8.6 \\
Sodium ion & concentration $(\mathrm{ppm})$ & \\
Initial & 9.0 & 9.0 \\
Final & 4.4 & 8.0 \\
\hline
\end{tabular}

$\mathrm{Cl}^{-}$ion concentrations with an increase in feed concentration was mainly because of two reasons. First was due to the increased $\mathrm{NaCl}$ concentrations in the feed solutions. The second reason was due to the restricted transport of sodium ion and chloride ion through IEMs because of decreased membrane capacity, which was due to the adhesion of the salt ions over the surface of the membrane which in turn was mainly because of the longer duration of previous performances. The higher the difference between the initial and final value effective was the process in the removal of $\mathrm{NaCl}$ and higher acid-base concentration with higher purity.

\section{Conclusions}

A novel resin-glass fiber-reinforced functionalized $\mathrm{PSu}$ based IEMs were prepared and characterized using FTIR, TGA, SEM, and contact angle measurements. The chemical stability of the prepared IEMs was determined by means of ionic conductivity, water absorption, and IEC. The BPM efficiency of prepared RPSu-PVP and PSDVBbased IEM systems were evaluated using $\mathrm{pH}$ and concentration measurements. Brine desalination performance results obtained for various parameters using RPSu-PVPbased IEM system were compared with PSDVB-based IEM system. Based on the results obtained for various process parameters such as CE (maximum of about $45 \%$ for RPSu-PVP and $38 \%$ for PSDVB), energy consumption (of about $0.41 \mathrm{Wh}$ for RPSu-PVP and $1.60 \mathrm{Wh}$ for PSDVB), acid-base production (maximum of about $0.010 \mathrm{~N}$ acid: $0.005 \mathrm{~N}$ base for RPSu-PVP and $0.008 \mathrm{~N}$ acid: $0.004 \mathrm{~N}$ base for PSDVB), and WDE (maximum as 
0.88 for RPSu-PVP and 0.21 for PSDVB), it was concluded that RPSu-PVP-based IEM system showed a better performance than that of the commercial PSDVB-based IEM system. In addition, electrical conductivity, salinity, and sodium-chloride ion concentration results were obtained for both types of IEM systems and compared.

Acknowledgments Financial support from the Board of Research in Nuclear Science (BRNS), Mumbai, India (Letter No. 2010/37C/1/ BRNS/826, Dated: 28-06-2010) is gratefully acknowledged. The authors thank for Goniometer facility help in Polymer Engineering and Colloids Science Laboratory, Chemical Engineering Department, IIT Madras.

Open Access This article is distributed under the terms of the Creative Commons Attribution 4.0 International License (http:// creativecommons.org/licenses/by/4.0/), which permits unrestricted use, distribution, and reproduction in any medium, provided you give appropriate credit to the original author(s) and the source, provide a link to the Creative Commons license, and indicate if changes were made.

\section{References}

Aritomi T, van der Boomgaard T, Strathmann H (1996) Current voltage curve of a bipolar membrane at high current density. Desalination 104:13-18

Badruzzaman M, Oppenheimer J, Adham S, Kumar M (2009) Innovative beneficial reuse of reverse osmosis concentrate using bipolar membrane electrodialysis and electrochlorination processes. J Membr Sci 326:392-399

Blaster J, Srinkantharajah S, Sumbharaju R, Pünt I, Lammertink RGH, Stamatialis DF, Wessling M (2010) Tailoring the interface layer of the bipolar membrane. J Membr Sci 365:389-398

Dias CR, de Pinho MN (1999) water structure and selective permeation of cellulose based membranes. J Mol Liquids 80:117-132

Frilette VJ (1956) Preparation and characterization of bipolar ionexchange membranes. J Phys Chem 60:435-439

Fu RQ, Xu TW, Wang G, Yang WH, Pan ZX (2003) PEG - catalytic water splitting in the interface of a bipolar membrane. J Colloid Interface Sci 263:386-390

Guan R, Zou H, Lu D, Gong C, Liu Y (2005) Polyethersulfone sulfonated by chlorosulfonic acid and its membrane characteristics. Eur Polym J 41:1554-1560

Kressman TRE, Tye FL (1956) The effect of current density on the transport of ions through ion-selective membranes. Discuss Faraday Soc 21:185-292

Krishnaveni V, Sangeetha D (2012) Desalination efficiency of a novel bipolar membrane based on functionalized polysulfone. Desalination 296:37-45

Krishnaveni V, Sangeetha D (2014a) Investigation on the application of polysulfone based bipolar membrane for desalination of water. Desalin Water Treat. doi:10.1080/19443994.2014.881751

Krishnaveni V, Sangeetha D (2014b) Evaluation of synthetic salt water desalination by using a functionalized polysulfone based bipolar membrane electrodialysis cell. Desalination 344:189-197
Krishnaveni V, Sangeetha D (2015) Evaluation of efficiency of brackish desalination ion exchange membranes using electrodialysis process. RSC Adv 5:73901-73913

Kumar M, Shahi VK (2010) Heterogeneous-homogeneous composite bipolar membrane for the conversion of salt of homologous carboxylates into their corresponding acids and bases. J Membr Sci 349:130-137

Liu Z, Zhu M, Yu P, Xu Y, Zhao X (2013) Pretreatment of membrane separation of glyphosate mother liquor using a precipitation method. Desalination 313:140-144

Ostwald W (1890) Elektrische eigenschaften halbdurchlassiger scheidewande. Z Phys Chem 6:71

Ren H, Wang Q, Zhang X, Kang R, Shi S, Cong W (2008) Membrane fouling caused by amino acid and calcium during bipolar membrane electrodialysis. J Chem Technol Biotechnol 83:1551-1557

Sachdeva S, Ram RP, Singh JK, Kumar A (2008) Synthesis of anion exchange polystyrene membranes for the electrolysis of sodium chloride. AIChE J 54:940-949

Shen J, Huang J, Liu L, Ye W, Lin J, Bruggen BV (2013) The use of BMED for glyphosate recovery from glyphosate neutralization liquor in view of zero discharge. J Hazard Mater 260:660-667

Shi S, Lee YH, Yun SH, Phan V, Hung X, Moon SH (2010) Comparisons of fish meat extract desalination by electrodialysis using different configurations of membrane stack. J Food Eng 101:417-423

Strathmann H, Koop GH (2000) Process economics of the electrodialytic water dissociation for the production of acid and base. In: Kemperman AJB (ed) Handbook on bipolar membrane technology. Twente University Press, Enschede, pp 193-218

Tanioka A, Shimizu K, Hosono T, Eto R, Osaki T (1999) Effect of interfacial state in bipolar membrane on rectification and water splitting. Colloids Surf A 159:395-404

Trivedi GS, Shah BG, Adhikary SK, Indusekhar VK, Rangarajan R (1997) Studies on bipolar membranes, part II. Conversion of sodium acetate to acetic and sodium hydroxide. React Funct Polym 32:209-215

Ulbricht M (2006) Advanced functional polymer membranes. Polymer 47:2217-2262

Volkov VV, Mchedlishvili BV, Roldugin VI, Ivanchev SS, Yaroslavtsev AB (2008) Membranes and nanotechnologies. Nanotechnol Russia 3:656-687

Wang Y, Zhang X, Huang C, Xu T (2011) Production of monoprotic, diprotic, and triprotic organic acids by using electrodialysis with bipolar membranes: effect of cell configurations. J Membr Sci 385:226-233

Wang X, Wang Y, Zhang X, Xu T (2012) In situ combination of fermentation and electrodialysis with bipolar membranes for the production of lactic acid: operational compatibility and uniformity. Bioresour Technol 125:165-171

$\mathrm{Xu} \mathrm{T}$, Yang W (2002) Effect of cell configurations on the performance of citric acid production by a bipolar membrane electrodialysis. J Membr Sci 224:1

Xue YH, Fu RQ, Fu YX, Xu TW (2006) Fundamental studies on the intermediate layer of a bipolar membrane V. Effect of silver halide and its dope in gelatin on water dissociation at the interface of a bipolar membrane. J Colloid Interface Sci 298:313-320

Zhu X, Liang Y, Pan H, Jian X, Zhang Y (2008) Synthesis and properties of novel H-bonded composite membranes from sulfonated poly (phthalazinone ether)s for PEMFC. J Membr Sci 312:59-65 